\title{
Epidemiological survey of early childhood caries in Cambodia
}

\author{
Bathsheba Turton ${ }^{1 *}$ (D), Tepirou Chher ${ }^{2}$, Wael Sabbah ${ }^{3}$, Callum Durward ${ }^{4}$, Sithan Hak ${ }^{2}$ and Arnaud Lailou ${ }^{5}$
}

\begin{abstract}
Background: The Southeast Asian Forum for Early Childhood Caries identified the need for more epidemiological surveys involving preschool children. To date, the only data on Early Childhood Caries in Cambodia come from convenience samples and only using the basic dmft index without measurement of the early signs of disease.

Methods: A cross-sectional survey on an epidemiological sample of Cambodian preschool children was conducted in conjunction with the fourth follow-up of the Cambodian Health and Nutrition Monitoring Study. Children were examined in a field setting using both the South East Asian Index for Early Childhood Caries as well as the 'pulpally involved, ulcerated, fistula, abscess' (pufa) index. Caregivers also participated in a short questionnaire covering dietary habits, oral health knowledge and behaviors, as well as the Family Impact Scale (FIS) for Oral-Health-Related Quality-of-Life.
\end{abstract}

Results: The sample included 3985 participants between birth and 4-years of age, across three provinces. There was an even sex distribution (50.7\% male). Overall $56.6 \%$ of participants had one or more carious lesions and $5.4 \%$ had one or more pulpally-involved teeth. There were some significant differences by age and location. Among those in the 3-year-old age group $84.9 \%$ had at least one decayed tooth, and $16.1 \%$ had one or more pulpally-involved teeth. There were differences in oral health knowledge and behaviors by province; those in Phnom Penh reported more favorable responses. Consumption of non-nutritious foods also differed between provinces with those in Phnom Penh consuming a higher mean number of sweet beverages per day. Those children with at least one pulpally involved tooth had a ten times greater chance of realizing an impact across the FIS.

Conclusions: Cambodian preschool children have a severe burden of dental caries and a high proportion of families are impacted by this problem. There were differences in oral health knowledge and behaviors according to province and this translated into differences in caries experience. The data from this study support the need for urgent action to address the issue of ECC in Cambodia.

Keywords: Early childhood caries, Cambodia, Oral-health-related quality-of-life, Family impact scale

\section{Introduction}

In 2016 the South East Asian (SEA) Forum for Early Childhood Caries identified the need for more epidemiological surveys of Early Childhood Caries in the region. In the past, most epidemiological surveys of dental caries in SEA have involved only children who were 6-years and older and did not record the presence of white spot lesions. This is an important omission given that white spot lesions represent both the latent burden of disease and also an opportunity for non-invasive interventions prior to cavitation [1].

\footnotetext{
* Correspondence: bethy.turton@gmail.com

${ }^{1}$ Melbourne Dental School, University of Melbourne, Melbourne, Australia

Full list of author information is available at the end of the article
}

Cambodia itself lacks any true epidemiological data on Early Childhood Caries. A number of initiatives grew out of the South East Asian Forum, including a published literature review [1] and a protocol for epidemiological surveys of ECC in SEA - the South East Asian Index for Early Childhood Caries (SEA-ECC) [2].

Within Cambodia there is a growing body of data pointing to the severity of caries experience among young children. The 2011 Cambodian National Oral Health Survey (CNOHS) reported a dmft of 9.0 for 6year-old children, a caries prevalence of $97 \%$, and a prevalence of pulpally-involved teeth of $86 \%$ [3]. This level of disease places Cambodia among the most severe

(c) The Author(s). 2019 Open Access This article is distributed under the terms of the Creative Commons Attribution 4.0 International License (http://creativecommons.org/licenses/by/4.0/), which permits unrestricted use, distribution, and reproduction in any medium, provided you give appropriate credit to the original author(s) and the source, provide a link to the Creative Commons license, and indicate if changes were made. The Creative Commons Public Domain Dedication waiver (http://creativecommons.org/publicdomain/zero/1.0/) applies to the data made available in this article, unless otherwise stated. 
in the world in terms of dental caries [1]. In addition, the CNOHS found that $99 \%$ of the carious lesions among children go untreated. Up until now the surveys on Early Childhood Caries in Cambodia have been based on convenience samples only, and have not included any data on quality of life; therefore it is difficult to convince the authorities to undertake country-wide action on the issue and to provide the level of evidence needed to inform policy [4-6].

The impacts of Early Childhood Caries are far reaching and can affect a child's ability to sleep, eat and grow [7]. In addition, the symptoms of the disease also affect others in the child's household who may have their sleep disrupted, or need to take time off work in order to seek treatment for the child [8]. Therefore, in addition to being a condition with high prevalence and severity with a range of negative impacts on the child, Early Childhood Caries in Cambodia is potentially creating a large and previously unmeasured impact on those in the child's household. The aim of the present paper is to describe the epidemiology, and family impacts of Early Childhood Caries in Cambodia and lay out an agenda for further investigations.

\section{Methods}

This cross-sectional study was conducted in combination with the on-going Cambodian Health and Nutrition Monitoring Study (CAHENMS). The focus of the CAHENMS is to observe the health, nutrition and diet of pregnant and lactating women along with their preschool children $(<5$ years of age) across three provinces. These provinces were identified by UNICEF for Enhanced Health Monitoring over a 3-year period. The sample size calculation was based on the three key indicators of health for preschool children; stunting, diarrhoea, and acute respiratory infection. Lists of pregnant and lactating women, and their respective children were obtained from village health volunteers and midwives in the selected Operational Districts until the target sample size of 1500 was reached. At baseline in 2016, the study enrolled children aged less than 24 months and 3 target groups of women: women at reproductive age, lactating women and pregnant women. Data in the present investigation were collected as part of the fourth follow-up in the CAHENMS in August 2017. Child participants were recruited from the three provinces (Phnom Penh, Kratie, and Ratinakiri) as they were born into the target communes; the sample began with 1500 children per province.

Ethical approval was provided by the National Ethics Committee for Health Research, Ministry of Health, Cambodia. Consent was obtained in writing from the caregivers at baseline and again verbally prior to participation of the caregiver in the questionnaire and the child in the intra-oral examination.

\section{Clinical examination}

Children were examined in a supine position with a mouth mirror and illumination from a hand-held torch. Appropriate infection control procedures were performed. Data were collected on caries status using the South East Asian Early Childhood Caries (SEA-ECC), and the PUFA index [9]. The SEA-ECC index has 10 codes; Code 0 represents a sound tooth surface, Code 1 represents early demineralisation such as a smooth white opacity or brown discolouration, Code 2 represents signs of early enamel breakdown (cavitation), Code 3 represents a where dentine is exposed, Code 4 is a filled and sound tooth, Code 5 represents a sealed and sound tooth, Code 6 represents a filled or sealed tooth with a visible carious cavitation, Code 7 represents a tooth that has been extracted due to caries, Code 8 represents and unerupted tooth, Code $\mathrm{X}$ represents a tooth that is to be excluded due to non-carious defects. A child was said to have 'any caries' if they had one or more teeth with a Code 1, Code 2, Code 3 , Code 4 , or Code 6 , or Code 7 . ' $\mathrm{d}_{1} \mathrm{mft}$ ' represented the number of teeth with lesions that were code 1 or higher. A child was said to have 'any cavitated lesions if they had one or more lesions of code 2 or higher. ' $\mathrm{d}_{2} \mathrm{mft}$ ' represented the number of teeth that had lesions that were cavitated (code 2 or above). A child was said to have 'any pufa' if there were one or more pulpally-involved teeth as defined by the PUFA index [9].

The CAHENMS involved eight data collection teams in a field environment. These teams were supplemented by a two-person dental team. The dental team included one calibrated examiner and one trained assistant. There were eight senior dental students who acted as examiners and underwent calibration training until all achieved a kappa score above 0.9 for the SEA-ECC index indicating near perfect agreement. Children received a toothbrush, toothpaste, and an oral health information brochure upon completion of the intra-oral examination.

\section{The questionnaire}

Questions were asked on diet, oral health knowledge and behaviours. For those in the Phnom Penh sample, the Family Impact Scale (FIS) was used as a measure of OralHealth-Related Quality-of-Life (OHRQoL). The FIS has been previously validated for use in a Cambodian population [10]. The instrument includes 8 questions across three subscales: family activities, family emotions, and conflict. The response options for each item were "Never" (scoring 0), "Once or twice" (scoring 1), "Sometimes" (scoring 2), "Often" (scoring 3), or "Every day or almost every day (scoring 4). A participant was said to have an 'impact' in a particular domain if they responded with a score 3 or above in any item. The questions on diet related to the frequency of consumption of non-nutritious (junk) foods over the preceding $24 \mathrm{~h}$. Interviewers underwent 
two training sessions prior to collecting data and a field supervisor was present or contactable throughout the data collection phase to answer any questions. The questionnaire was administered to the caregiver of each participating child. Questions on oral health knowledge and behaviours were asked as open-ended questions whereby participants were not prompted and had the opportunity to add as many responses as they choose. Responses were then categorised and those responses falling outside defined categories were considered as 'other'. Questions on diet were asked separately for each food group and the responding caregiver was asked to recall the number of times that the food item was consumed across six indicator time periods over the previous $24 \mathrm{~h}$.

\section{Data management and analysis}

Data were collected and managed using the existing database systems employed by the CAHENMS study. The system being used was the "KoBo Toolbox" and data were entered directly onto tablets for uploading at a location where there was WiFi access. Data were drawn from the KoBo Toolbox data base in a Microsoft Excel spreadsheet format prior to being transferred to IBM-SPSS (Version 23) for analysis. Differences in means between groups were tested using the Kruskal-Wallis test for non-parametric data and $t$-test for parametric data; differences in proportions among groups were tested using the Chi-squared test. The level of statistical significance was set at a $P$-value $<$ 0.05. Multivariate modelling was outside the scope of the present paper and will be presented as part of the reporting of the wider CANHEMS study.

\section{Results}

There was an even spread in terms of age and sex, with no statistically significant differences between groups of participants in each province (Table 1).

There was a severe experience of caries across the sample. Although only around half the children overall had one or more carious lesions, five out of six in the 3- year-old age-group had "any caries" and one in six had one or more pulpally-involved teeth. There were significant differences in caries experience by sex, age, and province; females and those in Phnom Penh had an approximately $10 \%$ higher prevalence of caries than other groups. There appeared to be a gradient whereby each year of life was associated with an approximately $20 \%$ higher prevalence of of cavitated lesions (Table 2).

Most of the participants believed that primary teeth were "important" although one-third of the participants did not believe that tooth decay is preventable (Table 3). Regarding methods for prevention, two-thirds knew that tooth brushing was a technique for preventing dental caries but only one in ten participants listed fluoride toothpaste as a means for prevention. Only one-third of participants had used toothpaste the previous day. There was a large, statistically significant difference in knowledge by location and those in Ratanakiri appeared to have a much poorer understanding of the causes of dental caries. There were significant differences in nonnutritious food consumption by location; those children in Phnom Penh consumed twice the amount of sweet drinks (including sweet milk beverages) compared with children from other regions. On the other hand, those children in the two outlying provinces of Ratanakiri and Kratie consumed around 1 packaged snack per day more than children in Phnom Penh.

Overall one third (33.5\%) of caregivers rated their child's oral health as "good" or "excellent" with no significant differences across provinces. Among Phnom Penh children aged 2-years and older $(n=481)$, there was no difference in FIS scale and subscale scores by age group. Around one in ten families reported one or more impacts across the FIS domains (Table 4). No participant had a maximum score, however 'floor effects' were evident with 402 (84.2\%) participants recording the minimum score of zero. Around one in ten families of children were categorised as having impacts across the FIS, and the emotions subscale appeared to be the most affected. Those children with one

Table 1 Sociodemographic characteristics of participants

\begin{tabular}{llll}
\hline & Male N (row \%) & Female N (row \%) & Total N (column \%) \\
\hline $\begin{array}{l}\text { Province } \\
\text { Phnom Penh }\end{array}$ & $542(48.1)$ & $584(51.9)$ & $1126(28.3)$ \\
Ratinakiri & $780(49.5)$ & $797(50.5)$ & $1577(39.6)$ \\
$\quad$ Kratie & $663(51.7)$ & $619(48.3)$ & $1282(32.2)$ \\
Age-group & & & $784(19.7)$ \\
$\quad<1$-year & $389(49.6)$ & $395(50.4)$ & $1372(34.5)$ \\
1-year & $671(48.9)$ & $701(51.1)$ & $1422(35.7)$ \\
2 -years & $719(50.6)$ & $703(49.4)$ & $404(10.1)$ \\
$\quad 2$ 3-years & $205(50.7)$ & $199(49.3)$ & $3985(100.0)$ \\
Overall & $1985(49.8)$ & $2000(50.2)$ & \\
\hline
\end{tabular}


Table 2 Clinical status by sociodemographic characteristics

\begin{tabular}{|c|c|c|c|c|c|c|c|c|c|c|c|c|}
\hline & $\begin{array}{l}\text { Any caries N } \\
\text { (Row \%) }\end{array}$ & $\begin{array}{l}p^{-} \\
\text {value }\end{array}$ & $\begin{array}{l}\text { Any Cavitated } \\
\text { Lesions N (Row \%) }\end{array}$ & $\begin{array}{l}p- \\
\text { value }\end{array}$ & $\begin{array}{l}\text { Any pufa N } \\
\text { (Row \%) }\end{array}$ & $\begin{array}{l}p- \\
\text { value }\end{array}$ & $\begin{array}{l}\mathrm{d}_{1} \mathrm{mft} \\
\text { Mean } \\
(\mathrm{SD})\end{array}$ & $\begin{array}{l}p^{-} \\
\text {value }\end{array}$ & $\begin{array}{l}\mathrm{d}_{3} \mathrm{mft} \\
\text { Mean } \\
(\mathrm{SD})\end{array}$ & $\begin{array}{l}\mathrm{p}- \\
\text { value }\end{array}$ & $\begin{array}{l}\text { Pufa } \\
\text { Mean } \\
\text { (SD) }\end{array}$ & $\begin{array}{l}p^{-} \\
\text {value }^{a}\end{array}$ \\
\hline \multicolumn{13}{|l|}{ Sex } \\
\hline Male & $1082(54.5)$ & 0.005 & $546(27.5)$ & 0.001 & $104(5.2)$ & 0.358 & $3.3(4.4)$ & $<0.001$ & $1.2(2.6)$ & $<0.001$ & $0.2(0.8)$ & 0.654 \\
\hline Female & 1172 (58.6) & & 646 (32.3) & & 111 (5.6) & & $3.8(4.7)$ & & $1.5(2.9)$ & & $0.2(1.0)$ & \\
\hline \multicolumn{13}{|l|}{ Age group } \\
\hline $\begin{array}{l}<12- \\
\text { months }\end{array}$ & $77(9.8)$ & $<0.001$ & $19(2.4)$ & $<0.001$ & $6(0.8)$ & $<0.001$ & $0.4(1.7)$ & $<0.001$ & $0.1(1.0)$ & $<0.001$ & $0.0(0.7)$ & 0.002 \\
\hline $\begin{array}{l}12-23 \\
\text { months }\end{array}$ & 763 (55.6) & & 269 (19.6) & & $37(2.7)$ & & $2.7(3.4)$ & & $0.7(1.7)$ & & $0.1(0.5)$ & \\
\hline $\begin{array}{l}24-35 \\
\text { months }\end{array}$ & $1068(75.1)$ & & $637(44.8)$ & & $107(7.5)$ & & $5.1(4.9)$ & & $2.0(3.1)$ & & $0.2(1.0)$ & \\
\hline $\begin{array}{l}36-47 \\
\text { Months }\end{array}$ & $343(84.9)$ & & $265(65.6)$ & & 65 (16.1) & & $7.0(5.6)$ & & $3.6(4.1)$ & & $0.5(1.7)$ & \\
\hline \multicolumn{13}{|l|}{ Province } \\
\hline $\begin{array}{l}\text { Phnom } \\
\text { Penh }\end{array}$ & $626(55.6)$ & 0.005 & 387 (34.4) & $<0.001$ & $66(5.9)$ & 0.307 & $3.7(4.8)$ & 0.008 & $1.7(3.1)$ & 0.018 & $0.1(0.7)$ & 0.181 \\
\hline Kratie & $856(54.3)$ & & $418(26.5)$ & & $90(5.7)$ & & $3.4(4.6)$ & & $1.1(2.6)$ & & $0.2(1.2)$ & \\
\hline Ratanakiri & $772(60.2)$ & & $387(30.2)$ & & $59(4.6)$ & & $3.6(4.2)$ & & $1.3(2.6)$ & & $0.1(0.7)$ & \\
\hline Total & $2254(56.6)$ & & $1192(29.9)$ & & 215 (5.4) & & $3.5(4.5)$ & & $1.3(2.8)$ & & $0.2(0.9)$ & \\
\hline
\end{tabular}

${ }^{a} P$-values presented are $X^{2}$ tests for comparisons of proportions and the Kruskal-Wallis test for comparison of means among groups within the same column

Table 3 Oral health knowledge and behaviours by health knowledge and behaviours by location ${ }^{a}$

\begin{tabular}{|c|c|c|c|c|}
\hline & Total N ${ }^{\mathrm{d}}$ (column \%) & Phnom Penh N (row \%) & Kratie N (row \%) & Ratinakiri N (row \%) \\
\hline \multicolumn{5}{|l|}{ Oral Health Knowledge } \\
\hline Primary teeth are important & $3116(80.2)$ & $834(82.7)$ & $1257(79.8)^{c}$ & $1025(78.9)^{c}$ \\
\hline Tooth decay is preventable & $2671(68.8)$ & $784(77.8)^{\mathrm{bd}}$ & $1094(69.4)^{b c}$ & $793(61.0)^{c d}$ \\
\hline \multicolumn{5}{|l|}{ Tooth decay can be prevented by } \\
\hline Tooth brushing & $2304(59.3)$ & $666(66.1)^{\mathrm{bd}}$ & $937(59.5)^{\mathrm{bc}}$ & $701(54.0)^{c d}$ \\
\hline Fluoride toothpaste & $370(9.5)$ & $361(35.8)^{\mathrm{bd}}$ & $3(0.2)^{b}$ & $6(0.5)^{d}$ \\
\hline Avoiding sweet food & $248(6.4)$ & $217(21.5)^{\mathrm{bd}}$ & $15(1.0)^{\mathrm{b}}$ & $16(1.2)^{d}$ \\
\hline Visiting the dentist & $927(23.9)$ & $9(0.9)^{b d}$ & $594(37.7)^{\mathrm{bc}}$ & $324(24.9)^{\mathrm{cd}}$ \\
\hline Preventing in other ways & $438(11.3)$ & $30(3.0)^{\mathrm{bd}}$ & $298(18.9)^{b c}$ & $110(8.5)^{\mathrm{cd}}$ \\
\hline \multicolumn{5}{|l|}{ Tooth decay is caused by: } \\
\hline Sugar & $1794(46.2)$ & $834(82.7)^{\mathrm{bd}}$ & $959(60.9)^{\mathrm{bc}}$ & $1(0.1)^{c d}$ \\
\hline Bacteria & $37(1.0)$ & $7(0.7)^{\mathrm{bd}}$ & $3(0.2)^{b c}$ & $27(2.1)^{\mathrm{cd}}$ \\
\hline Inherited/genetic & $104(2.7)$ & $2(0.2)^{b d}$ & $33(2.1)^{\mathrm{bc}}$ & $69(5.3)^{\mathrm{cd}}$ \\
\hline Other cause & $1163(30.0)$ & $144(14.3)^{\mathrm{bd}}$ & $579(36.7)^{\mathrm{bc}}$ & $440(33.9)^{\mathrm{cd}}$ \\
\hline Brushed the child's teeth yesterday & $1847(49.9)$ & $494(51.1)^{\mathrm{bd}}$ & $705(47.1)^{\mathrm{bc}}$ & $648(52.4)^{\mathrm{cd}}$ \\
\hline Used toothpaste when brushing & $1361(36.8)$ & $260(26.9)^{\mathrm{bd}}$ & $662(44.2)^{b c}$ & $439(35.5)^{\mathrm{cd}}$ \\
\hline Mean number of sweet drinks/day & $1.9(\mathrm{SD} 2.6)$ & $3.1(2.3)^{b}$ & $1.5(3.0)^{\mathrm{bd}}$ & $1.4(1.7)^{\mathrm{d}}$ \\
\hline Mean number of packaged snacks/day & $3.3(2.7)$ & $2.5(1.7)^{\mathrm{b}}$ & $4.0(3.4)^{\mathrm{bcd}}$ & $3.1(2.4)^{\mathrm{cd}}$ \\
\hline
\end{tabular}

${ }^{\mathrm{a}} \mathrm{N}$ represents the number of participants who agree (eg. The number of participants to state that primary teeth are important) or who or list an item (eg. Tooth brushing) in response to open ended questions about oral health knowledge and behaviours

$\mathrm{b}, \mathrm{c}, \mathrm{d}$ Means that in groups within the same row with a common super script letter have a statistically significant different $\left(\mathrm{P}=<0.05 ; \mathrm{X}^{2}\right.$ or $t$-test $)$ 
Table 4 Prevalence of impacts across the Family Impact Scale and subscale scores for Phnom Penh participants

\begin{tabular}{|c|c|c|c|c|}
\hline & Family Impact Scale & Activities Subscale & Emotions Subscale & Conflict Subscale \\
\hline \multicolumn{5}{|l|}{ Gender } \\
\hline Male & $26(10.4)^{a}$ & $6(2.4)$ & $23(9.3)^{a}$ & $3(1.2)^{\mathrm{a}}$ \\
\hline Female & $41(16.5)$ & $12(4.8)$ & $37(14.9)$ & $10(4.0)$ \\
\hline \multicolumn{5}{|l|}{ Age-group } \\
\hline$<12$-months & $0(0.0)$ & $0(0.0)$ & $0(0.0)$ & $0(0.0)$ \\
\hline $12-23$ months & $4(10.0)$ & $2(5.0)$ & $3(7.5)$ & $0(0.0)$ \\
\hline 24-35 months & $47(14.0)$ & $13(3.9)$ & $42(12.5)$ & $11(3.3)$ \\
\hline 36-47 Months & $16(15.7)$ & $3(2.9)$ & $15(14.7)$ & $2(2.0)$ \\
\hline \multicolumn{5}{|l|}{ Caries experience } \\
\hline No carious lesions & $5(3.5)^{b}$ & $5(3.5)$ & $1(0.7)^{\mathrm{b}}$ & $1(0.7)^{\mathrm{b}}$ \\
\hline Any cavitated lesions & $59(22.4)^{b}$ & $13(4.9)$ & $56(21.3)^{b}$ & $12(4.6)^{b}$ \\
\hline Any pufa & $10(24.4)^{a}$ & $2(4.9)$ & $9(22.0)^{a}$ & $2(4.9)$ \\
\hline Overall & $67(13.5)$ & $18(3.6)$ & $60(12.0)$ & $13(2.6)$ \\
\hline
\end{tabular}

${ }^{a} P<0.05 ; X^{2}$ test for differences in impacts by gender, presence of cavitated lesions, or pulpally involved lesion

${ }^{b} P<0.005 ; X^{2}$ test differences in impacts by presence of, or pulpally involved lesion

or more cavitated lesions and those children who had one or more pulpally-involved teeth had a seven-fold greater chance of realising an impact across the FIS.

\section{Discussion}

This study represents the first opportunity to examine ECC in a Cambodian context using an epidemiological survey; it confirms the findings of previous convenience samples in demonstrating that the caries experience of preschool children is severe, and affects a large proportion of both urban and rural children. Although the FIS is a well-recognized instrument for measuring OHRQoL, this study is also the first time that the FIS has been used in an epidemiological survey and it was able to demonstrate differences in impacts according to the presence of disease.

This study is unique in that there was an attempt to incorporate a participant reported indicator for caries disease experience. The instrument selected in this case was the FIS due to the fact that it had been previously validated for use in a Cambodian population. Possibly the Early Childhood Oral Health Impact Score might have been a better epidemiological tool for describing OHRQoL at population level, as reported by other authors [8]. However, the FIS has demonstrated that ECC is not just an issue for the affected children, but also their households; ECC in this study was associated with a higher prevalence of impacts on the family. It is also interesting to note that the 'Family Emotions' subscale appeared to be the most affected; families experienced feelings of being upset or guilty about the state of their child's mouth. It appears that ECC can undermine the functioning of a household, particularly if members of the household experience additional stressors as a result of dental caries. For example if parents lose sleep or cannot attend work as a result of the symptoms of dental caries in their child.

The prevalence and severity of ECC in Cambodia appears to be similar to that observed in urban areas of the Lao Peoples Democratic Republic and the Philippines. In contrast, children in neighboring Thailand have benefited from a reduction in Early Childhood Caries in recent years as a result of a nationwide oral health strategy, and those in Singapore appear to have the lowest prevalence in the region due to favorable socio-demographic status and water fluoridation. Comparisons of ECC across the SEA region are however difficult given the variable sampling techniques and the fact that much of the data is now out of date [1]. The SEA Early Childhood Caries Forum identified the need for more recent and higher quality epidemiological data; therefore the aim of this paper was to present a description of ECC in a representative sample of Cambodian children, ahead of a more complex and multidisciplinary exploration of how dental caries is associated with a range of other behavioural, developmental, and nutritional factors.

The finding that one in six children have one or more pulpally-involved teeth by the age of 3-years is a remarkable statistic with wide-reaching implications in terms of disease burden. Around half of the lesions observed in the present study were only in the enamel, demonstrating an opportunity for intervention before cavitation occurs. If the non-cavitated lesions could be managed in the preschool age group using simple and non-invasive methods, then that would significantly reduce severity of the symptoms that are experienced by those children as they grow older. A reduction in caries experience might logically have a positive impact on a child's ability to eat, 
sleep and learn well; future investigations will address this research question.

Some differences were observed in the prevalence and severity of ECC across provinces and this might partly be explained by the differences in consumption of nonnutritious high-sugar foods. Children in Phnom Penh had a higher consumption of sugary drinks, which are known to be the largest contributor of free sugars in children's diets. In contrast, those children in more remote areas had a higher consumption of packaged snacks which, although being non-nutritious, contain less sugar than sugary drinks [11]. If those in the urban areas are consuming more sugar then it is also worth noting that approximately half of the lesions in the Phnom Penh sample were cavitated in contrast to just one-third of lesions in the two other provinces. This is the first epidemiological survey to provide a preliminary examination of the consumption of non-nutritious snacks among this age-group and the present findings provide some cause for alarm. WHO has recently updated its recommendations concerning the amount of free sugars which can be safely consumed [12]. However further investigations are needed in Cambodia to define sugar consumption both in terms of quantity and in terms of the associated social factors and behavioral factors that accompany that consumption.

High consumption of non-nutritious foods and their effect on health could create challenges for the Cambodian health system and workforce [12]. While sugar is recognized as the primary driver of the caries process, the impact of non-nutritious food consumption on other health conditions must also be considered. A better understanding of the complex relationship between the presence of carious lesions and the presence of other health conditions such as nutritional disorders is needed. Multi-sectorial initiatives should be implemented to reduce the consumption of non-nutritious foods in young children, and to support the Cambodian population to align with the WHO recommendation for sugar consumption; that just $5 \%$ of calorific energy intake should be sourced from 'added sugar' [11].

Despite the uniformly high sugar consumption, it does appear that differences in knowledge and behaviors may have moderated some of the disease experience of the preschool children when we compare the urban and rural samples. Those in Phnom Penh had a lower ratio of pulpally-involved teeth to cavitated lesions (PUFA ratio [9]) and this could possibly be explained by the higher proportion of caregivers in Phnom Penh who appeared to have a more favorable understanding of dental caries and the ways in which it can be prevented. The relationship between oral health literacy and dental caries experience is an investigation that could be explored as a way of influencing oral health behaviors.
The results of this study, presenting data on both the observable signs of dental caries together with evidence of impacts on the family unit, provides compelling evidence that urgent action is needed to address the ECC issue in Cambodia. Caries is an entirely preventable disease. A recent pilot study of the 'Cambodia Smile' intervention in Kampong Speu province demonstrated success in reducing dental caries among 2-year old children through the use of primary health care workers to deliver an oral health intervention [13]. Further validation of such lowcost public health interventions is needed in order to justify policy change and implementation of preventive programs on a wider scale.

\section{Conclusion}

The paper presented descriptive data on ECC and highlighted the need for further multidisciplinary exploration of how dental caries interacts with other behavioral, developmental, and nutritional factors. The study makes it clear that preschool children in Cambodia suffer from a severe burden of dental caries which also has impacts on others in the household. There is strong evidence that ECC is a pressing issue for the Cambodian population and urgent action should be taken in order to reduce the burden of disease using evidence-based approaches.

\section{Abbreviations \\ CAHENMS: Cambodia Health and Nutrition Monitoring Study; CNOHS: Cambodia National Oral Health Survey; ECC: Early childhood caries; FIS: Family impact score; OHRQoL: Oral-health-related quality-of-life; PUFA: The Pulpally involved, Ulcerated, Fistula and Abscess index; SEA: South East Asian; SEA-ECC: The South East Asian Index for Early Childhood Caries}

\section{Acknowledgements}

The authors would like to acknowledge the work of the examiners and field staff who undertook the data collection in challenging conditions: Chengkim Lean, Chanveata Pot, Chandaroth Heng, Pheanyvita, Sokmean Peng, Rang Sey Hay, Sopheap Orn, Hongthein Hy, Lengeave Hong, Sam At Sang, Koinghuy Leang, Kimser Ngan, Phallin Uy, Heng lay Veng, Khemey Ea, Nary Sun, Serey Hing under the supervision of Dr. Sokuntheary Hou.. Ms. Somphos Som coordinated the field data collection. The collaborating partners on this project are RACHA (Reproductive and Child Health Association), UNICEFCambodia, the French National Institute for Sustainable Development Institute (IRD), and the Oral Health Bureau, Preventive Medicine Department, Ministry of Health Cambodia.

\section{Authors' contributions}

BT analysed data, and drafted the manuscript. BT, TC, WS, CD, and AL contributed to study design, editing of the manuscript. BT, TC, SH contributed to collection of data. All authors read and approved the final manuscript.

\section{Funding}

Funding for this project was provided by a grant from The Borrow Foundation.

\section{Availability of data and materials}

The datasets used and/or analysed during the current study are available from the corresponding author on reasonable request. 


\section{Ethics approval and consent to participate}

Ethics approval was provided by the National Committee for Health Research (Ministry of Health, Cambodia). Consent for children to participate in intra-oral examinations was obtained through the legal guardians.

\section{Consent for publication}

Not Applicable.

\section{Competing interests}

The authors declare that one of the authors (WS) is on the editorial board of $\mathrm{BMC}$ oral health

\section{Author details}

'Melbourne Dental School, University of Melbourne, Melbourne, Australia. ${ }^{2}$ Oral Health Bureau, Department of Preventive Medicine, Ministry of Health, Phnom Penh, Cambodia. ${ }^{3}$ Kings College London, London, UK. ${ }^{4}$ University of Puthisastra, Phnom Penh, Cambodia. ${ }^{5}$ UNICEF-Cambodia, Phnom Penh, Cambodia.

Received: 10 July 2018 Accepted: 31 May 2019

Published online: 13 June 2019

\section{References}

1. Khitdee C. The epidemiology of early childhood caries. Thai Dent Public Health J. 2017;22(supp 1):3-10.

2. Bureau of Dental health. Department of Health, Ministry of Public Health, Thailand. Guidelines of epidemiological survey of Early Childhood Caries (ECC). Bangkok: Ministry of Health; 2016.

3. Chher T, Turton B, Hak S, Beltran E, Courtel F, Durward C, Hobdell M. Dental caries experience in Cambodia: findings from the 2011 Cambodia National Oral Health Survey. J Int Oral Health. 2016;1:1-16.

4. Todd RV, Durward CS, Chot C, So PK, Im P. The dental caries experience, oral hygiene and dietary practices of preschool children of factory workers in Phnom Penh, Cambodia. Int J Paediatr Dent. 1994;4:173-8.

5. Turton B, Durward CS, Manton DJ. Early childhood caries and maternal caries experience in a convenience sample of Cambodian pre-schoolers. Pediatr Dent J. 2015:25:14-8.

6. Turton BJ, Durward CS, Manton DJ, Bach K, Yos C. Socio-behavioural risk factors for early childhood caries (ECC) in Cambodian preschool children: a pilot study. Eur Arch Paediatr Dent. 2016;2:97-105.

7. Sheiham A. Dental caries affects body weight, growth and quality of life in pre-school children. Br Dent J. 2006;201:625-6.

8. Thomson WM, Foster Page LA, Malden PE, Gaynor WN, Nordin N. Comparison of the ECOHIS and short-form P-CPQ and FIS scales. Health Qual Life Outcomes. 2014;12:36

9. Monse B, Heinrich-Weltzien R, Benzian $\mathrm{H}$, Holmgren C, van Palenstein Helderman W. PUFA-an index of clinical consequences of untreated dental caries. Community Dent Oral Epidemiol. 2010:38:77-82.

10. Khoun T, Malden PE, Turton BJ. Oral health-related quality of life in young Cambodian children: a validation study with a focus on children with cleft lip and/or palate. Int J Paediatr Dent. 2018;28:326-34.

11. World Health Organization. Guideline: sugars intake for adults and children Newcastle: WHO; 2015

12. Jacobs B, Men C, Bigdeli M, Hill PS. Limited understanding, limited services, limited resources: patients' experiences with managing hypertension and diabetes in Cambodia. BMJ Glob Health. 2017;2:e000235.

13. Turton B, Durward C, Soeun S, Crombie F, Manton D. Cambodia Smile - 2year follow-up of a community based Early Childhood Caries (ECC) intervention. Santiago: Congress of the International Association of Paediatric Dentistry; 2017.

\section{Publisher's Note}

Springer Nature remains neutral with regard to jurisdictional claims in published maps and institutional affiliations.

Ready to submit your research? Choose BMC and benefit from:

- fast, convenient online submission

- thorough peer review by experienced researchers in your field

- rapid publication on acceptance

- support for research data, including large and complex data types

- gold Open Access which fosters wider collaboration and increased citations

- maximum visibility for your research: over $100 \mathrm{M}$ website views per year

At BMC, research is always in progress.

Learn more biomedcentral.com/submissions 